\title{
CORRESPONDENCE
}

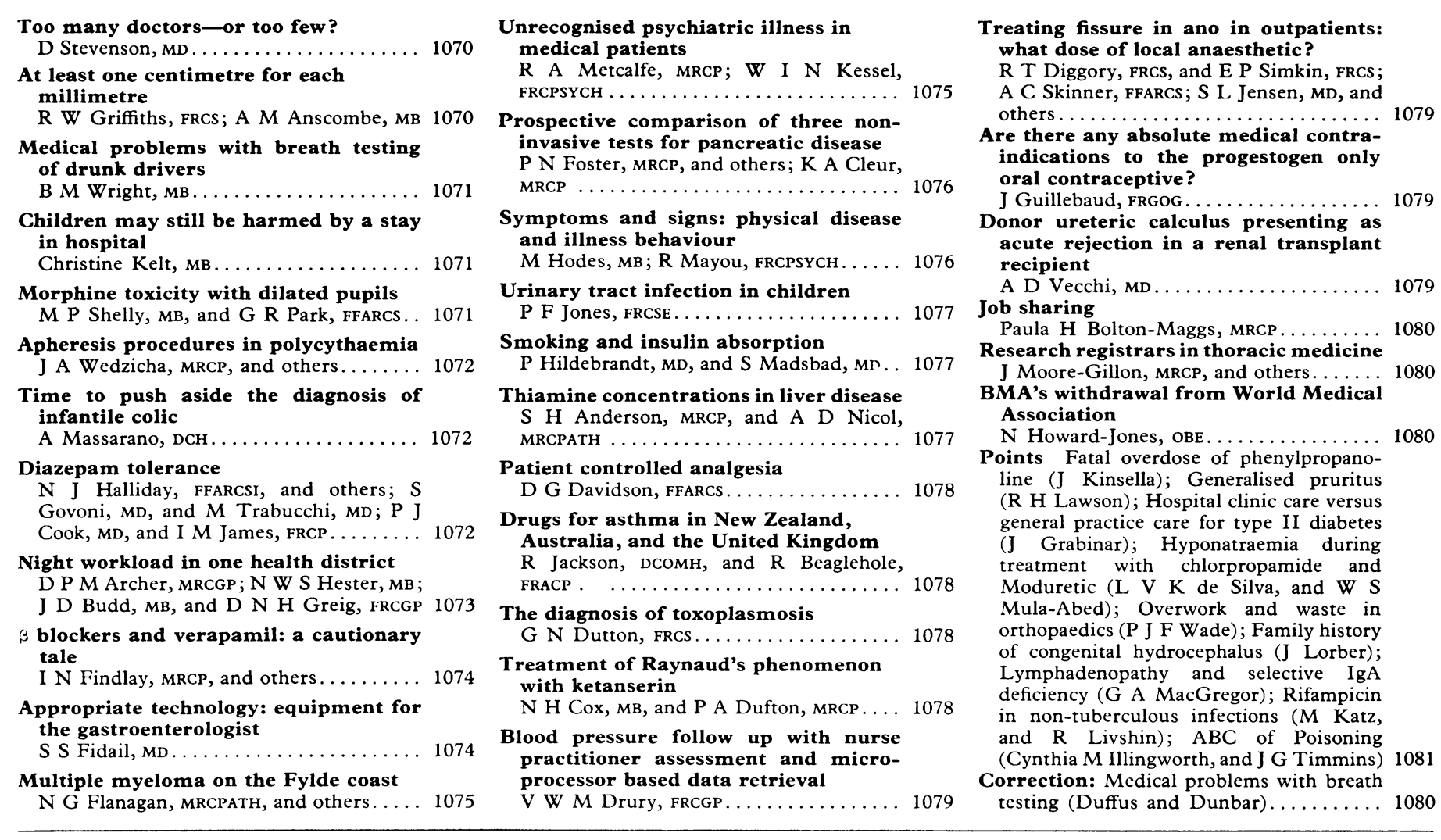

We may shorten letters to the editor unless the authors specifically state that we may not. This is so that we can offer our readers as wide a selection of letters as possible. We receive so many letters each week that we have to omit some of them. Letters must be typed with double spacing between lines and must be signed personally by all their authors, who should include their degrees. Letters critical of a paper may be sent to the authors of the paper so that their reply may appear in the same issue.

Correspondents should present their references in the Vancouver style (see examples in these columns). In particular, the names and initials of all authors must be given unless there are more than six, when only the first three should be given, followed by et al; and the first and last page numbers of articles and chapters should be included.

Too many doctors-or too few?

SIR,-You report a survey of unemployment among doctors (6 October, p 936), and Scrutator repeats the arguments that too many doctors are being trained and that medical student numbers should be reduced (p 932). Meanwhile, an obstetrician complains of overwork during a colleague's holiday as no locum could be found (p 916).

Barring a war or other man made disaster it seems likely that fewer and fewer worker hours will be required to produce the goods and services that we consume. This gives our community the opportunity of more leisure or of using our working time to produce higher quality goods and services-including better health care. Surely it is both shortsighted and a counsel of despair to advocate training fewer doctors? If in all disciplines we train only enough people to fill the paid jobs at present on offer then many able people will get no higher education at all.

Numbers of schoolteachers in training have already been reduced despite what would seem an obvious need for more education. If our society chooses to share work and leisure then we shall need more doctors-how many would we need if the normal working week were 35 hours or if we each had three months' holiday a year? I would feel I had better prospects of using my life constructively as an unemployed doctor than as an unemployed person who had been refused any higher education because there was no specific job to educate me for.

Unemployed doctors (and teachers, plumbers, bricklayers) might just nianage to help change our society into one where work and leisure and goods and services are equitably shared. An uneducated, unemployed (perhaps

\section{At least one centimetre for each millimetre}

SIR,-I was surprised and disappointed to find that the leading article on resection margins in cutaneous malignant melanoma by $\mathrm{Dr} F \mathrm{H} \mathrm{J}$ Rampen (29 September, p 782) potentiated the often repeated misrepresentation of the work of Handley. ${ }^{2}$ Contrary to Dr Rampen's summary, Handley described post mortem the centrifugal lymphatic spread of melanoma unemployable) subproletariat such as our present system seems bent on producing might see no way out for itself but either heroin or violent revolution.

Let's be a little hopeful and a little unselfish and offer medical education to as many as possible of those who can benefit from it.

David Stevenson

Department of International

Community Health,

Liverpool School of

Tropical Medicine,
Liverpool L3 5 QA around a focus of metastatic melanoma in the groin of a 34 year old woman. The area adjacent to the scar of the excision of the primary lesion at the ankle was apparently healthy. Handley specified that he had not had the opportunity to investigate tumour permeation around a primary lesion. None the less, on the basis of observations at this one necropsy he 
advocated a skin excision margin one inch from the edge of the primary tumour with resection of an additional two inches of fat and deep fascia beneath the undermined skin edges; he also advocated resection of some muscle.

Dr Rampen's review is inaccurate in several other particulars. Day et al did not indicate that microscopic satellites were absent around lesions less than $1 \mathrm{~mm}$ thick-rather they wrote that no satellites were detected around 168 lesions of $0.75 \mathrm{~mm}$ or less thick; for 151 patients with $0.76-1.50 \mathrm{~mm}$ thick lesions $7 / 151(4 \cdot 6 \%)$ were found to have satellites. ${ }^{3}$ Furthermore, Elder et al indicated that they found no local recurrences in their patients (which they defined as reappearances of biopsyproved melanoma within or contiguous to the definitive excision scar). ${ }^{4}$

Dr Rampen's analysis ${ }^{5}$ of the WHO study concluded that a $9 \cdot 4 \%$ rate for local recurrence after excision of stage I melanomas with tumour free excision margins of $2 \mathrm{~cm}$ or less was unacceptably high. We have recently found in a minimum 10 year follow up study of stage I melanomas treated with conventional wide excision margins (most $5 \mathrm{~cm}$ or greater) that the rate of local tumour recurrence was $26 / 258(10 \%){ }^{7}$ Not only should patients treated for melanoma be followed up for prolonged periods to determine the accurate rate of local tumour recurrence, but the relative proportions of thin and thick tumours should be detailed as well as the surgical excision margins. ${ }^{8}$ Despite wide resection margins thick tumours are likely to be associated with an increased rate of local tumour recurrence, which will reflect simply the continuing growth of what were initially microscopic satellites outwith the margins of the resection-however wide they may have been.

The work of Day et $a l^{3}$ did indicate a $63 \%$ incidence of histologically proved microsatellites in the tissues surrounding melanomas greater than $4 \mathrm{~mm}$ thick, but they did not relate the position of these micrometastases to the margins of the primary tumour. We require to know the position of satellite lesions as well as their incidence in conventional wide margin excision specimens if we are to set out rationally recommendations on margins of excision for stage I malignant melanoma of the skin. A prospective randomised trial of varying excision margins related to primary tumour thickness and observed incidence of both micrometastases in adjacent tissue and eventua rate of local tumour recurrence over prolonged follow up is long overdue.

RICHARD W GRIFFITHS

\section{Department of Plastic and \\ Jaw Surgery, \\ Bristol BS16 1IE}

1 Handley WS. The pathology of melanotic growths in relation to their operative treatment; I. Lancet 1907 relation to

2 Handley WS. The pathology of melanotic growths in relation to their operative treatment; II Lancet 1907; $\mathrm{i}: 996-1003$.

3 Day CL, Harrist TJ, Gorstein F, et al. Malignan melanoma; prognostic significance of "microscopic satellites" in the reticular dermis and subcutaneous fat. Ann Surg 1981;194:108-12.

4 Elder DE, Guerry D, Heiberger RM, et al. Optimal resection margin for cutaneous malignant melanoma. Plast Reconstr Surg 1983;71:66-72.

5 Rampen FHJ. Melanoma of the skin; the problem of resection margins. Eur f Cancer 1981;17:589-90.

Cascinelli N, Van der Esch EP, Breslow A, Morabito A, Bufalino R. Stage I melanoma of the skin: the
problem of resection margins. Eur $f$ Cancer $1980 ; 16$ problem
$1079-85$

7 Griffiths RW, Briggs JC. Long term follow up in cutaneous malignant melanoma; the relationship of maximal tumour thickness to disease free survival, disease recurrence and death. Br $\mathcal{F}$ Plast Surg (in press).

8 Roses DF, Harris MN, Rigel D, Carrey Z, Friedman $\mathbf{R}$, Kopf AW. Local and in-transit metastases following definitive excision for primary cutane
malignant melanoma. Ann Surg 1983;198:65-9.

SIR,-Dr F H J Rampen does less than justice to Ackermann and Scheiner ${ }^{1}$ in his leading article on what constitutes adequate excision of malignant melanoma. The American authors' argument runs as follows.

Local satellite metastases indicate that more widespread metastasis has already taken place. Excision of these local satellite metastases would therefore not eradicate the tumour and would be expected to have no effect on survival.

Surgical intervention can thus either eradicate lesions which have not metastasised (these tend to be "thinner") or at least allow histological assessment of prognostic features which may suggest that metastasis is likely to have already taken place and that surgery is already too late (these lesions tend to be "thicker"). In either case a wide margin of excision is unnecessary.

Adequate control of local disease by surgery may be important for cosmetic or psychological reasons where a cure cannot be achieved. For the same reasons it is important to avoid subjecting the patient to unnecessarily mutilating operations where no improvement in survival will result.

Allen M Anscombe

County Laboratory,

Dorchester,
Dorset DT1 1XD

1 Ackermann AB, Scheiner AM. How wide and deep is wide and deep enough? A critique of surgical practice in excisions of primary cutaneous malignant

\section{Medical problems with breath testing of drunk drivers}

SIR,-I was sorry to see the $B M F$ joining the Daily Express in publishing yet another letter (29 September, p 831) designed to cast doubts on the reliability of breath alcohol testing. The story it tells has already been repeated in the Sunday Times and carries a ring of authority as a result of having appeared in your columns. Like Dr Peter Duffus and Dr James A Dunbar, I occasionally receive such letters from hopeful solicitors, but this is one of the least convincing that I have read. In the first place, Dr Duffus and Dr Dunbar ignore one of the basic maxims in the business: "What the subject says he has drunk is not evidence."

The subject, on the other hand, seems to have been well briefed in the art of evading conviction. Taking a stiff whisky after an accident and before the police arrive is a well known ploy for confusing the issue and is illegal in many countries. Refusing a confirmatory blood test is another-rather newploy. Blood test results cannot be argued with, while breath tests as a result of the press campaign against them are only too easy to dispute.

The consultant gastroenterologist whose report got the subject off the hook was no doubt an expert in his discipline, but this was not breath alcohol. If stomach contents had reached the subject's mouth the breath concentration would have been much higher than $50 \mu \mathrm{g} / 100 \mathrm{ml}$ because even diluted whisky has an alcohol concentration about a hundred times that of blood. The mouth concentration would fall rapidly so that the second sample would have given a much lower reading. The close agreement between the two readings is strong evidence that they were both recording true breath alcohol.

The Home Office is about to publish the results of an enormous blood/breath correlation study, and I have little doubt that these will be similar to those of its previous study which showed that not one out of 620 subjects would have been wrongly convicted on a breath test. ${ }^{1}$
I hope, however, that the Home Office will continue the policy which I have always advocated, of allowing a blood test to anyone who wants it, and will not allow those who refuse it to dispute the breath test result. ${ }^{2}$

\section{Rickmansworth, Herts}

B M WRIGHT

1 Isaacs MDJ, Hunt DJ. A survey analyses of breath and blood samples provided by subjects within the option range. London: HMSO, 1984.

(Letter.) The Times,

*** A correction to the letter from Dr Duffus and Dr Dunbar is published on p 1080.-ED,

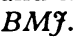

\section{Children may still be harmed by a stay} in hospital

SIR,-I must take issue with Minerva over a vital omission from her abstract (29 September, p 838) of Shannon's paper about children in hospital and subsequent behaviour problems. ${ }^{1}$ Minerva concludes that "admission to hospital need not be seen as a risk to a child's later development," whereas the New Zealand group take pains to emphasise that their work was done "in an enlightened paediatric setting ... where there is unlimited parental visiting and facilities for mothers to stay."

Figures from the recent Mitchell report on children in hospital in Scotland ${ }^{2}$ show that of nearly 90000 children discharged from Scottish hospitals in 1980 only $53 \%$ were from designated children's hospitals or departments. This leaves $47 \%$ being nursed in adult wards, where the state of paediatric enlightenment can be very far from ideal. As Mitchell comments, "a deplorable state of affairs."

The Mitchell report's other concern is with the size of paediatric units, advocating increased centralisation of resources into units of at least 50 beds. While our association participated in the preparation of the report and endorses its recommendations, we have two main fears about the way it might be implemented. Firstly, closure of local paediatric units may result in yet more children being admitted to adult wards. Secondly, insufficient emphasis may be placed on the problems of parents having to travel to more distant paediatric units and on Mitchell's recommendation that "parents must receive assistance to maintain the closest possible links with their children as of right."

\section{Christine Kelt}

\section{National Association for the \\ Welfare of Children in}

Edinburgh

1 Shannon FT, Ferguson DM, Dimond ME. Early hospital admissions and subsequent behaviour proble

2 Working Group of the National Medical Consultative Committee. Scottish Home and Health Department/ Scottish Health Service Planning Council. Children in hospital: arrangements for inpatient care. Edin-

\section{Morphine toxicity with dilated pupils}

SIR,-Dr Michael Nielsen and Dr John Henry (15 September, p 681) refer to using naloxone for the diagnosis and treatment of comatose patients with small pupils. While in the acutely poisoned patient pinpoint pupils and depressed consciousness and respiration are 